\title{
Optimising treatment for post-operative lung cancer recurrence
}

\author{
Dragan Subotic ${ }^{1}$, Paul Van Schil ${ }^{2}$ and Bogdan Grigoriu ${ }^{3}$
}

Affiliations: ${ }^{1}$ Clinic of Thoracic Surgery, Clinical Centre of Serbia, University of Belgrade Faculty of Medicine, Belgrade, Serbia. ${ }^{2}$ Dept of Thoracic and Vascular Surgery, University Hospital, Antwerp, Belgium. ${ }^{3}$ Dept of Pulmonology, University of Medicine and Pharmacy, lasi, Romania.

Correspondence: Dragan Subotic, Clinic of Thoracic Surgery, Clinical Centre of Serbia, Koste Todorovica 26, 11000 Belgrade, Serbia. E-mail: profsuboticlagmail.com

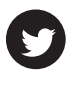

@ERSpublications

The second lung resection is a valuable option for post-operative lung cancer recurrence http://ow.ly/U8z3c

Surgical treatment offers the best chances for long-term survival in patients with primary nonsmall cell lung cancer (NSCLC). However, long-term survival after surgery remains less than $50 \%$, mostly due to a $30-77 \%$ rate of tumour recurrence. Unlike the distant type of recurrence that is treated nonsurgically in the vast majority of patients, local or loco-regional recurrence, which occurs in $4.6-24 \%$ of patients after complete resection ( $\sim 80 \%$ of cases in the first 2 years) [1], raises several concerns related to the optimal therapeutic approach.

Unfortunately, literature data are not always helpful in practice. For example, 5-year loco-regional recurrence rates are between 15 and 38.5\% [2], and the incidence of local recurrence in early-stage lung cancer of $10-15 \%$ [3], or a mean disease-free interval of 14.1-19.8 months, that is similar to distant recurrent disease [4]. Failure to demonstrate the advantage of complete lymphadenectomy over nodal sampling in terms of local recurrence or survival in patients operated for T1-2, N0 or T1-2, N1 disease, makes the clinical approach more complex [5]. Moreover, the impact of intensified follow-up on overall survival or local recurrence detection could not be clearly demonstrated. In $\sim 50-67 \%$ of patients, recurrence will appear before a scheduled control because of the onset of symptoms [6].

Finally, switching to seventh edition of the TNM (tumour, node, metastasis) staging system automatically led to the stage migration, reaching $21 \%$ in some studies. The only study of the role of computed tomography (CT) in post-operative recurrence detection demonstrated a high negative predictive value of $95 \%$, but a positive predictive value of only $53 \%$ ( $94 \%$ sensitivity and $87 \%$ specificity) [7]. For positron emission tomography, although it is more sensitive than CT in detecting recurrent tumours (97-100\%), variations of the cut-off values for the standardised uptake value $(\geqslant 4.5-\geqslant 10)$ make its clinical application difficult, together with its specificity (62-100\%) that is lower than for CT.

The role of prognostic factors after surgery is more evidence-based, owing to awareness of the poor 5-year survival of patients in stages IA and IB ( $73 \%$ and $58 \%$, respectively). This also applies to the high recurrence rate in patients with stage I after complete resection (25-50\%) [8]. The results of these studies really helped to identify patients who would probably benefit from adjuvant therapy.

Among tumour markers, although increased serum concentrations of carcinoembryonic antigen (CEA) are rare $(17 \%)$, persistently high post-operative CEA levels were found to be a strong indicator of poor prognosis. In $55-70 \%$ of patients with CEA values of 5-10 ng. $\mathrm{mL}^{-1}$, an early recurrence will develop [9].

Of the many analysed clinical and pathological prognostic factors, vascular invasion, lymphatic vessel and visceral pleural invasion have been identified as clearly unfavourable in terms of survival and incidence of

Received: Sept 072015 | Accepted after revision: Sept 262015

Conflict of interest: None declared.

Copyright OERS 2016 
recurrence [10]. Many studies have reported difficulties in accurately differentiating between intravascular and lymphatic vessel invasion. Moreover, visceral pleural invasion was reported as a significant poor prognostic factor regardless of "N" status [11].

As to the role of molecular genetics in the field of post-operative tumour recurrence, molecular profiling of gene expression in tumour samples, combined with clinical and pathological variables, offers promise in predicting prognosis more accurately [12].

Currently, of the five largest chemotherapy adjuvant trials, the NCIC JBR.10 and ANITA trials showed an overall survival benefit that was persistent over time. It was $8.4 \%$ at the 7 -year follow-up time point for the ANITA trial [13]. The remaining three trials (BLT, IALT and ALPI) confirmed a survival benefit after 5 years, but not after $7[14,15]$. Therefore, although currently not widely accepted, suggestions that adjuvant treatment might be appropriate in patients with intravascular, lymphatic or visceral pleural invasion with or without nodal involvement, sounds reasonable in terms of recurrence prevention. However, it requires confirmation in further trials.

As for adjuvant radiation therapy, based on earlier data, it is currently only recommended for patients with resected N2 disease [16]. However, these data reflected outdated radiation techniques, which may have contributed to the detrimental outcome. Two recent randomised trials, using modern techniques, support such a statement. The first trial demonstrated lower recurrence rates and better 5-year survival in patients with N0 disease [17], while the second trial confirmed only the lower recurrence rate in patients with post-operative stage T1-3, N0-2, M0 NSCLC [18]. Some data suggest that post-operative irradiation could also be of benefit in patients with resected N1 disease who are at high risk of local relapse [19]. The ongoing LungART trial randomises patients with completely resected N2 disease between those receiving post-operative radiotherapy and those who do not [20].

Concerning the optimal extent of the first lung resection, two ongoing trials are comparing lobectomy versus sublobar resection for peripheral stage IA NSCLC (Cancer and Leukemia Group B 140503 and JCOG 0802 trials) [21]. They will determine more clearly whether sublobar resection is a valid oncological treatment for stage IA NSCLC.

The ACOSOG-Z4032 trial investigated the role of sublobar resection with brachytherapy versus sublobar resection alone [22]. Brachytherapy did not reduce the incidence of local recurrence after sublobar resection, underlying the importance of adequate surgical margins of sublobar resections.

Surgery for post-operative loco-regional recurrence or metachronous tumours is possible in up to $4 \%$ of patients [23]. They usually undergo a "completion pneumonectomy", meaning removal of the remaining lung after the first lung resection. The reason is that the great majority of patients requiring this type of surgery previously underwent lobectomy or bilobectomy, and rarely a sublobar resection.

In patients with positive bronchial margins after lobectomy, metachronous bronchogenic cancer or with metastases after surgery for primary cancer, a completion pneumonectomy is also an option. In contrast, patient selection in the case of local recurrence is more challenging and insufficiently evidence-based. Only a few series exceed 50 patients, dealing mostly with the appropriateness of this operation in the light of quite a high operative morbidity and mortality, switching the focus from the disease stage towards the operative risk assessment. Based on the literature and our experience, patients older than 65-70 years, with unfit general condition, renal insufficiency or other major cardiological or combined cardiopulmonary comorbidities, are not suitable candidates for this kind of surgery. Intrapericardial dissection is usually necessary even without direct pericardial involvement of the recurrent tumour. Equally, completion pneumonectomy should be performed in dedicated surgical centres.

Despite the alleged high complication rate, operative mortality in the majority of series published in the past 15 years is about or slightly above 12\% [24-29], operative morbidity is under $40 \%$ and the bronchopleural fistula rate is $\sim 10 \%$ (table 1 ). The wide range of the reported mortality rates, in some series reaching $33.3 \%$ and operative morbidity up to $62.6 \%$ [30], are the consequence of different definitions of complications and inclusion of all types of indications, rather than being strictly procedure-related. Furthermore, reports that the second procedure is better tolerated by the cardiopulmonary system than a one-stage pneumonectomy, combined with a reported 5 -year survival $\sim 40 \%$ in many series, make this operation a reasonable option, provided the patient selection is adequate. There is a broad consensus that bronchial stump protection is of utmost importance, especially in right-sided operations (figure 1).

As presented in table 1, both earlier and recent survival data are consistent throughout the literature, with 5 -year survival rates being $\sim 40 \%$ in many series. The worse survival rates reported, for example $23 \%$ in one series, are counterweighted by the high proportion $(>65 \%)$ of stage III patients. The evidence indicates better survival of patients with squamous cell versus adenocarcinoma [2] and a significant influence of disease stage (stages I and II versus stage III). 


\begin{tabular}{|c|c|c|c|c|c|c|}
\hline First author [ref.] & Year & $\begin{array}{c}\text { Patients } \\
n\end{array}$ & $\begin{array}{c}\text { 30-day } \\
\text { post-operative } \\
\text { mortality }\end{array}$ & $\begin{array}{l}\text { Operative } \\
\text { morbidity }\end{array}$ & $\begin{array}{l}\text { Bronchopleural } \\
\text { fistula }\end{array}$ & $\begin{array}{l}\text { 5-year } \\
\text { survival }\end{array}$ \\
\hline MASSARD [24] & 1995 & 37 & 10.8 & & & 44.5 \\
\hline TRONC [25] & 1999 & 77 & 10.5 & 22 & 10.4 & 29 \\
\hline MiLLeR [30] & 2002 & 115 & 17.6 & 62.6 & 7 & \\
\hline TERZI [26] & 2002 & 59 & 3.4 & 30 & & 25 \\
\hline Guginno [23] & 2004 & 55 & 11.9 & 58.2 & 12.7 & 44 \\
\hline JUNGRAITHMAYR [27] & 2004 & 26 & 33.3 & 29.3 & & 23 \\
\hline Chataigner [28] & 2007 & 69 & 12.7 & 40.6 & 10 & 41 \\
\hline CARDillo [29] & 2012 & 152 & 10.5 & 55.1 & 7.9 & $48.9^{\#} / 23.9^{9}$ \\
\hline
\end{tabular}

Data are presented as \%, unless otherwise stated. " : squamous cell; ${ }^{\text {१!: }}$ adenocarcinoma.

Chemotherapy is the third available treatment option. In patients with the metastatic type of recurrence, chemotherapy is the treatment of choice. The exception is mono/oligo-metastatic recurrences that can be treated either with local therapy (surgery and/or radiotherapy) alone or combined with chemotherapy. As the risk of relapse is higher in more advanced stages, most of these patients have previously undergone adjuvant or neoadjuvant therapy with a third generation platinum-based drug combination. It is still questionable whether these patients should receive, in case of recurrence, a second-line or a first-line protocol (monotherapy) or a new/re-challenge with a platinum doublet combination, because literature data are limited. In fact, in some studies, patients with post-operative recurrence underwent both the firstand second-line protocols after previous neoadjuvant/adjuvant chemotherapy, so that no separate analysis is available. Most experts argue that patients relapsing after surgery (including those with adjuvant/ neoadjuvant chemotherapy) should be considered as chemotherapy naïve and treated with the first-line protocol. However, the influence of other clinical factors relevant for this choice is unknown. To the best of our knowledge, there is only one trial dealing with chemotherapy in patients relapsing after

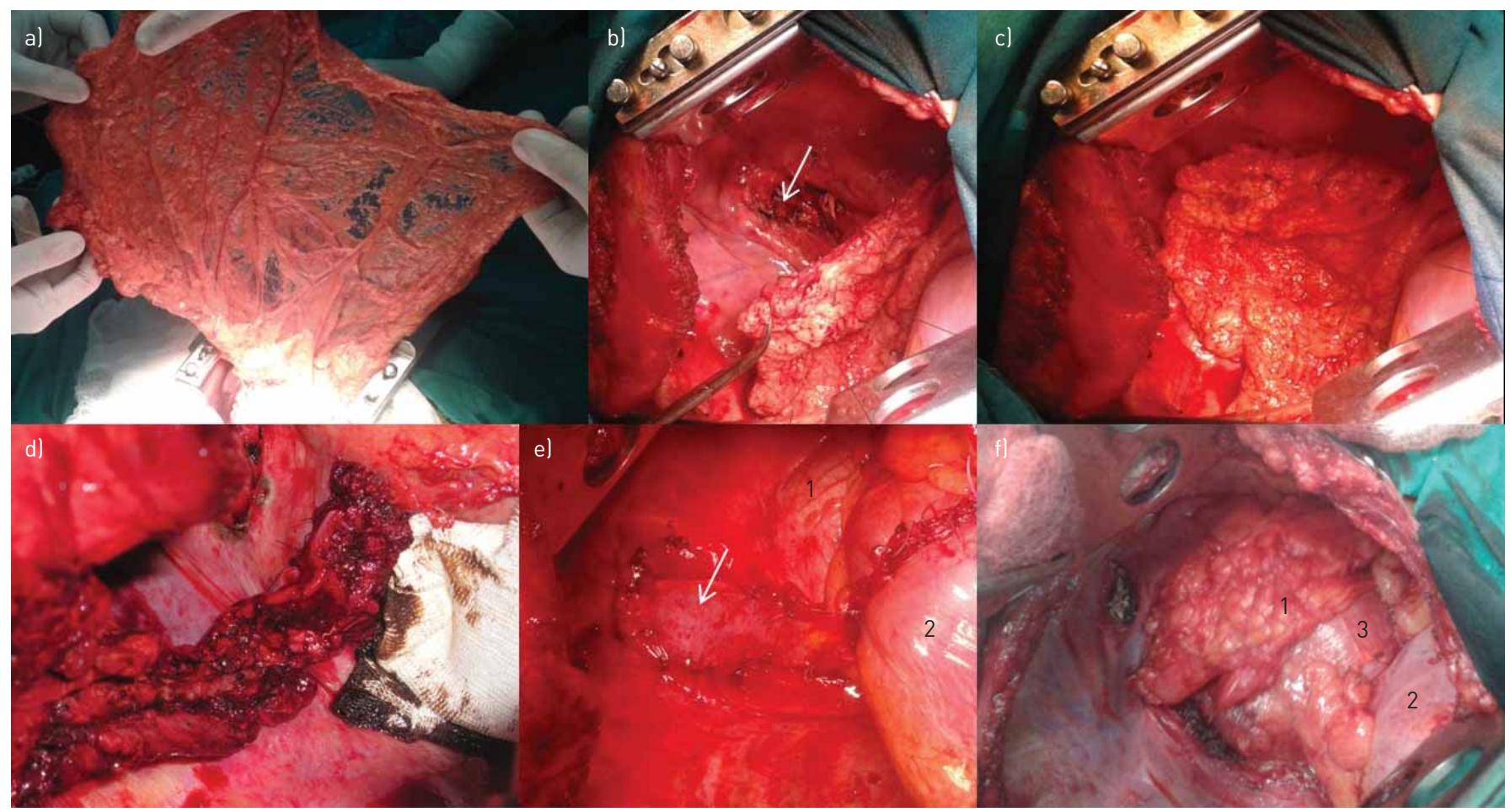

FIGURE 1 Techniques for bronchial stump protection. Upper row: transposition of the omentum; al vascularised omental flap harvested, ready for transposition; b) omental flap transposed into the thorax (arrow: sutured bronchus); c) omental flap sutured to the bronchus and surrounding structures. Lower row: d) intercostal muscle flap; e) diaphragm flap (arrow: flap; 1: pericardium; 2: diaphragm); f) pericardial fat (1: vascularised fat sutured to the bronchus; 2: diaphragm; 3: pericardium). 
chemotherapy [31]. This trial tends to support this attitude and showed a nonsignificant increase in progression-free survival and overall survival with doublet chemotherapy. There was a more favourable outcome for epidermoid tumours and those relapsing after 12 months of previous therapy. However, major recruiting difficulties made this trial severely underpowered.

To summarise, the choice of the optimal treatment for post-operative lung cancer recurrence is not sufficiently evidence-based. Repeat surgery is a valuable option, but the selection of patients remains a major challenge. Due to the limited literature, the choice of the appropriate drug combination for this type of recurrence relies upon local practice and case by case discussion in a multidisciplinary team.

\section{References}

1 Hung JJ, Hsu WH, Hsieh CC, et al. Post-recurrence survival in completely resected stage I non-small cell lung cancer with local recurrence. Thorax 2009; 64: 192-196.

2 Varlotto JM, Recht A, Flickinger JC, et al. Varying recurrence rates and risk factors associated with different definitions of local recurrence in patients with surgically resected, stage I nonsmall cell lung cancer. Cancer 2010; 116: $2390-2400$

3 Pepek JM, Chino JP, Marks LB, et al. How well does the new lung cancer staging system predict for local/regional recurrence after surgery? A comparison of the TNM 6 and 7 systems. J Thorac Oncol 2011; 6: 757-761.

4 Kelsey CR, Marks LB, Hollis D, et al. Local recurrence after surgery for early stage lung cancer: an 11-year experience with 975 patients. Cancer 2009; 115: 5218-5227.

5 Darling GE, Allen MS, Decker PA, et al. Randomized trial of mediastinal lymph node sampling versus complete lymphadenectomy during pulmonary resection in the patient with N0 or N1 (less than hilar) non-small cell carcinoma: results of the American College of Surgery Oncology Group Z0030 Trial. J Thorac Cardiovasc Surg 2011; 141: 662-670.

6 Walsh GL, O'Connor M, Willis KM, et al. Is follow-up of lung cancer patients after resection medically indicated and cost-effective? Ann Thorac Surg 1995; 60: 1563-1570.

7 Korst RJ, Kansler AL, Port JL, et al. Accuracy of surveillance computed tomography in detecting recurrent or new primary lung cancer in patients with completely resected lung cancer. Ann Thorac Surg 2006; 82: 1009-1015.

8 Devita DV, Hellman S, Rosenberg SA, eds. Cancer: Principles and Practice of Oncology. 6th Edn. Philadelphia, Lippincott Williams \& Wilkins, 2001.

9 Benamore R, Shepherd FA, Leighl N, et al. Does intensive follow-up alter outcome in patients with advanced lung cancer? J Thorac Oncol 2007; 2: 273-281.

10 Egermann U, Jaeggi K, Habicht JM, et al. Regular follow-up after curative resection of nonsmall cell lung cancer: a real benefit for patients? Eur Respir J 2002; 19: 464-468.

11 Shimizu K, Yoshida J, Nagai K, et al. Visceral pleural invasion is an invasive and aggressive indicator of non-small cell lung cancer. J Thorac Cardiovasc Surg 2005; 130: 160-165.

12 Lee ES, Son DS, Kim SH, et al. Prediction of recurrence-free survival in postoperative non-small cell lung cancer patients by using an integrated model of clinical information and gene expression. Clin Cancer Res 2008; 14: 7397-7404.

13 Douillard JY, Rosell R, De Lena M, et al. Adjuvant vinorelbine plus cisplatin versus observation in patients with completely resected stage IB-IIIA non-small-cell lung cancer (Adjuvant Navelbine International Trialist Association [ANITA]): a randomised controlled trial. Lancet Oncol 2006; 7: 719-727.

14 Waller D, Peake MD, Stephens RJ, et al. Chemotherapy for patients with non-small cell lung cancer: the surgical setting of the Big Lung Trial. Eur J Cardiothorac Surg 2004; 26: 173-182.

15 Arriagada R, Bergman B, Dunant A, et al. Cisplatin-based adjuvant chemotherapy in patients with completely resected non-small-cell lung cancer. N Engl J Med 2004; 350: 351-360.

16 Postoperative radiotherapy in non-small-cell lung cancer: systematic review and meta-analysis of individual patient data from nine randomised controlled trials. PORT meta-analysis trialists group. Lancet 1998; 352: 257-263.

17 Trodella L, Granone P, Valente S, et al. Adjuvant radiotherapy in non-small cell lung cancer with pathological stage I: definitive results of a phase III randomized trial. Radiother Oncol 2002; 62: 11-19.

18 Mayer R, Smolle-Juettner FM, Szolar D, et al. Postoperative radiotherapy in radically resected non-small cell lung cancer. Chest 1997; 112: 954-959.

19 Machtay M, Paulus R, Moughan J, et al. Defining local-regional control and its importance in locally advanced non-small cell lung carcinoma. J Thorac Oncol 2012; 7: 716-722.

20 Le Péchoux C, Dunant A, Faivre-Finn C, et al. Postoperative radiotherapy for pathologic N2 non-small-cell lung cancer treated with adjuvant chemotherapy: need for randomized evidence. J Clin Oncol 2015; 33: 2930-2931.

21 Nakamura K, Saji H, Nakajima R, et al. A phase III randomized trial of lobectomy versus limited resection for small-sized peripheral non-small cell lung cancer (JCOG0802/WJOG4607L). Jpn J Clin Oncol 2010; 40: 271-274.

22 Fernando HC, Landreneau RJ, Mandrekar SJ, et al. Impact of brachytherapy on local recurrence rates after sublobar resection: results from ACOSOG Z4032 (Alliance), a phase III randomized trial for high-risk operable non-small-cell lung cancer. J Clin Oncol 2014; 32: 2456-2462.

23 Guggino G, Doddoli C, Barlesi F, et al. Completion pneumonectomy in cancer patients: experience with 55 cases. Eur J Cardiothorac Surg 2004; 25: 449-455.

24 Massard G, Lyons G, Wihlm JM, et al. Early and long-term results after completion pneumonectomy. Ann Thorac Surg 1995; 59: 196-200.

25 Tronc F, Grégoire J, Rouleau J, et al. Techniques of pneumonectomy. Completion pneumonectomy. Chest Surg Clin N Am 1999; 9: 393-405.

26 Terzi A, Furlan G, Terrini A, et al. Completion pneumonectomy: experience with 47 cases. Thorac Cardiovasc Surg 1995; 43: 52-56.

27 Jungraithmayr W, Hasse J, Olschewski M, et al. Indications and results of completion pneumonectomy. Eur J Cardiothorac Surg 2004; 26: 189-196. 
28 Chataigner O, Fadel E, Yldizeli B, et al. Factors affecting early and long term outcomes after completion pneumonectomy. Eur J Cardiothorac Surg 2008; 33: 837-843.

29 Cardillo G, Galetta D, Van Schil P, et al. Completion pneumonectomy: a multicentre international study on 165 patients Eur J Cardiothorac Surg 2012; 42: 405-409.

30 Miller DL, Deschamps C, Jenkins GD, et al. Completion pneumonectomy: factors affecting operative mortality and cardiopulmonary morbidity. Ann Thorac Surg 2002; 74: 876-883.

31 Moro-Sibilot D, Audigier-Valette C, Merle P, et al. Non-small cell lung cancer recurrence following surgery and perioperative chemotherapy: comparison of two chemotherapy regimens (IFCT-0702: a randomized phase 3 final results study). Lung Cancer 2015; 89: 139-145. 